\title{
In Pursuit of the Virtuous Life: From the Perspective of the Traditional Chinese Medical Wisdom
}

\author{
Kuangfei Xie \\ Humanity and Politics Department of Nanjing University of Traditional Chinese Medicine, NanJing, China
}

Email address:

09110010012@fudan.edu.cn

\section{To cite this article:}

Kuangfei Xie. In Pursuit of the Virtuous Life: From the Perspective of the Traditional Chinese Medical Wisdom. Science Journal of Public Health. Vol. 3, No. 6, 2015, pp. 878-882. doi: 10.11648/j.sjph.20150306.23

\begin{abstract}
To fundamentally cope with the health crisis of the modern people, we need to turn to the ancient medical wisdom for the wise guidance. Eventually, the great wisdom of health and happiness lies in the consistently virtuous life. Living the virtuous life means following the laws of nature naturally. The virtuous consciousness of one's existence and self is closely linked with the consciousness of one's health. In addition, we also need to find the ontological significance of the healthy body to the spiritual fitness. Finally, in order to make sure about the close connection between the virtuous life and the healthy life, we need to find back the ancient wisdom of the state or horizon of life, which essentially determines the health of a person.
\end{abstract}

Keywords: Virtuous Life, the Traditional Chinese Medical Wisdom, Virtues

\section{Introduction}

The virtuous life is not only happy, but also healthy. Since being healthy means being physically, mentally, and even spiritually sound, the truly healthy life, undoubtedly, has much to do with the virtuous life. Being virtuous means getting rid of all the unhealthy habits and reducing the unnecessary desires. Moreover, living the virtuous life also means learning to be contented with what one has and not getting greedy, which has a lot to do with the problem of whether one is truly healthy or not. According to the Classical traditional Chinese book of medicine, Yellow Emperor's Canon of Medicine -Plain Conversation, When Huangdi asked Qibo," I am told that people in ancient times all could live for one hundred years without any signs of senility. But people nowadays begin to become old at the age of fifty. Is it due to the changes of environment or the violation of the way to preserve health?" Qibo answered, "The sages in ancient times who knew the Dao, namely, the tenets for cultivating health, followed the rule of Yin and Yang and adjusted Shushu, namely, the ways to cultivate health. They were moderate in eating and drinking, regular in working and resting, avoiding any overstrain. That is why they could maintain a desirable harmony between the mind and body, enjoying good health and a long life."[1] (p3) Health is closely linked with one's mental state and spiritual state. Whether one can be genuinely healthy or not largely depends on whether one can live in harmony with nature, others and the inner self.

\section{Living the Consistently Virtuous Life: The Great Wisdom of Health}

Eventually, the great wisdom of health and happiness lies in the consistently virtuous life. Living the virtuous life means following the laws of nature naturally. According to the wisdom of Traditional Chinese medicine, the body of a person is similar to the inner small universe, while the whole nature is the outer huge universe. Living the virtuous life enables the virtuous agents to live in harmony with both themselves and the nature, which definitely lays the solid foundation for the long-term and sustainable happiness." When the sages in ancient times taught the people, they emphasized the importance of avoiding the vicious and evil atmosphere and keep the mind free from avarice. In this way, the essential energy in the body will be in harmony, and the essential spirit will be kept within, and diseases will have no way to occur." [1] (p. 5) Health consists in activities in accordance to with the virtues, especially with the highest virtues. The external goods, including the high-quality medical equipments, are necessary and significant to the health and fitness of a person only to a rather limited extent. What determines our health is not the tangible medical conditions, but the intangible mental and spiritual conditions of the virtuous agents. The advanced and accumulated 
knowledge concerning medicine and health is far from being enough. What we urgently need is the great wisdom about health. The traditional Chinese medical wisdom has certainly provided a wider and broader perspective about how to attain the significant goal of being essentially healthy.

\subsection{Living the Virtuous Life: Finding the Connections with the Feelings of the Soul}

The virtuous consciousness of one's existence and self is closely linked with the consciousness of one's health. Without the necessary virtues serving as the solid basis, the modern people will be turned into the morally and healthily "Hollow Men", with only the "Shape without form, shade without colour" as well as the "Paralyzed force, gesture without motion." [2] In other words, the so-called health of the modern people is only the rootless health or the hollow health that is not deeply rooted into the eternal and fundamental virtues. The health issue can never be merely outsourced to just the professional doctors or hospitals. The virtuous agents themselves are supposed to be responsible for their health. With the life style of the modern people being increasingly modernized and even alienated, the modern people are giving up the ancient wisdom of health, consequently, they suffer a lot from all kinds of illnesses caused by the dehumanizing lifestyle.

The ancient medical wisdom of China repeatedly remind us that, eventually, it is just up to ourselves to determine whether we are healthy or not. Only when the inner life energy is closely connected with outer natural energy can they maintain the healthy life state. "Therefore people in ancient times all lived in peace and contentment, without any fear. They worked, but never overstrained themselves, making it smooth for Qi, namely, the flow of the natural energy of life go forward smoothly." [1] (p. 5) In fact, the intangible flow of the emotional energy or the spiritual energy of life plays an even more significant role in determining whether a person is genuinely healthy or not.

\subsection{Body and Soul: The Ontological Significance of the Healthy Body to the Spiritual Fitness}

Body, by itself, constitutes the one of the ends or purposes of life. Body is not supposed to be used as the means or the instrument to another utilitarian goal. What's more, the body shouldn't be treated as an object for arbitrary manipulation, either. From the perspective of the traditional Chinese medicine, it is essential for us to feel our body, talk to our body, share our intimate feelings with the body, embrace our body and listen to our body with all heart and soul. The body is the trustworthy companion of the soul. Not only is the body and mind one, but also the body and soul is the one. The body itself constitutes the material basis of the spiritual activities. Just like we need to do our utmost to take care of our souls, we also need to take good care of our bodies. Building a sound body lays the sound foundation for the sound mind and sound soul. There is indeed something fundamentally wrong with the modern lifestyle of the modern people when we look at the issue of health from the perspective of traditional Chinese medicine. Furthermore, there is even something essentially wrong with the ultimate objective towards which the modern people have been striving. The materially prosperous and rich life has not led to the natural result of the spiritual balance and the inner mental satisfaction. Consequently, the spiritual health that constitutes the core of health has almost become the "mission impossible". Just like man does not live by bread alone, health does not depend on the objective medical conditions alone.

\subsection{What Is Man and What Is Health}

"The species man can be defined not only in anatomical and physiological terms; its members share basic psychic qualities, the laws which govern their mental and emotional functioning, and the aims for a satisfactory solution of the problem of human existence." [3] To answer the essential question of what is man, we need to take both the emotional dimension and the spiritual dimension of man into consideration. In fact, the defect of spontaneity and naturalness has led to the inevitable loss of the genuine identity of each individual. That the human nature and the general social atmosphere can have contradictions or conflicts and hence that not only the human bodies, but also the human emotions or even the human relations in general can be sick, is an important assumption that has been made clear by the traditional Chinese medical wisdom, most extensively in the great Chinese medicine book of Yellow Emperor's Canon of Medicine. Therefore, to fundamentally and systematically cure the diseases, it is essential for us to have a truly comprehensive understanding about what man is and what health is.

\section{The State or Horizon of Life: What Essentially Determines the Health of a Person}

The most important element in the consideration of the issue of health is, from the perspective of the traditional Chinese medical wisdom, the state or horizon of a person. There is the spiritually harmonious horizon of life and there is also the mentally harmonious horizon of life. In addition, there is the physically harmonious horizon of life.

\subsection{Grasp the Law of Nature: The Highest Horizon of Life}

Just like Huangdi said, "I am told that there were so-called Zhenren (immortal beings) in ancient times who could grasp the law of nature. They followed the principles of Yin and Yang, inhaling fresh air, cultivating their spirit and keeping their muscles integrated. So their life expectancy was as long as that of the earth and heavens. This is their Dao (the art of preserving health) of life." [1] (p. 9-11.).

Man does not only belong to the animal kingdom. The essential functioning of man, unlike animals, is not largely determined by the genetic factors or the natural instincts. The 
essential functioning of man is more determined or affected by the mental or spiritual elements. Despite the fundamental fact that man is part of nature, man can transcend it, both mentally and spiritually. As a result, the spiritual transcending will naturally lead to the physical transcending. As a matter of fact, the core of the traditional Chinese medicine wisdom is not the so-called tangible and scientific part of it. What matters most about it is actually the intangible, non-scientific part of it. That is to say, the traditional Chinese medicine is not only a science, but also an art, not only a particular discipline, but also the comprehensive and essential wisdom concerning the issue of health. The distinctive place for the the cultivation of the inner virtues and the healthy moral sentiments has been vividly revealed in the great books of the traditional Chinese medicine. "Life is an ultimate and self-dependent reality", because it has "the autonomy of life". Every life is a monadic being, which "has a world of its own because it has an experience of its own." [4] When the individual life, as a inner universe by itself, can grasp the law of nature and accordingly follow the great life wisdom of nature, it can indeed reach the highest horizon of life.

\subsection{Supreme Morality: The Fundamental Reason of Supreme Health}

"In the middle ancient times, there were so-called Zhiren (perfect person) who possessed supreme morality and the tenets of cultivating health, abiding by the change of Yin and Yang, adapting themselves to the changes of seasons, abandoning secular desires, avoiding distraction and roaming around on the earth and in the heavens. So they could see and hear things and voices beyond the eight directions. Such a practice and self-cultivation enabled them to keep fit and prolong their life." [1] (p. 11) Prevention is much better than cure itself. In other words, the best cure of the diseases is not to let the diseases happen at all by following the natural wisdom of life. The reason why people become ill is that they have not followed the natural laws of life. Just like when we do not obey the natural law of gravitation, we will be severely punished by nature, we will also pay the price of health when we don't obey the natural of health. The supreme morality is the indispensable and essential element of the natural law of health. From the perspective of the traditional Chinese medicine, the supreme morality or virtues are not only morally meaningful in guiding our social behaviors, but also an intangible life energy that can nourish solidify the health of each individual life. As another sage of Confucianism, Mencius, said that "The feeling of commiseration is essential to man, that the feeling of shame and dislike is essential to man, that the feeling of modesty and complaisance is essential to man, and that the feeling of approving and disapproving is essential to man. The feeling of commiseration is the principle of benevolence. The feeling of shame and dislike is principle of righteousness. The feeling of modesty and complaisance is the principle of propriety. The feeling of approving and disapproving is the principle of knowledge. Men have these four principles just as they have their four limbs. Since all men have these four principles in themselves, let them know how to give them all their development and completion, and the issue will be like that of fire which has begun to burn, or that of a spring which has begun to find vent. Let them have their complete development, and they will suffice to love and protect all within the four seas. Let them be denied that development, and they will not suffice for a man to serve his parents with." [5] Similarly, when it comes to the issue of health, we also need to fully develop our moral potential so that we can provide the body with the inner, vital life energy.

\subsection{Creating the Harmonious Environment for the Health}

"The third kind of people was known as Shengren (Sages) who were capable of living in a harmonic environment between the earth and the heavens and adapting themselves to the wind from the eight different directions. In daily life they could properly tackle their interest and desire and their mind was free from anger and discontentment. They did not try to draw themselves away from secular customs, and also worn luxurious clothes. Physically, they tried not to exhaust their body; mentally, they freed themselves from any anxiety, regarding peace and happiness as the target of their life, and taking self-contentment as the symbol of achievement. As a result, their body was seldom susceptible to decline and their spirit was never subject to exhaustion. That was why they could live over one hundred years." [10] (p 11) Generally, this kind of life horizon is what the majority of us can spiritually follow and pursue. The body can not be separated from the self or the whole life. It is also proposed that the inner spirit or the inner harmony should be regarded as the center of of the picture of bodily health. Eventually, it is the virtuous agent himself that grows sick or achieves health. No single illness, whether physical or psychological, or spiritual, should be thought of as just the accidents that happen without the intangible or tangible reasons. The health of the body can not be isolated from the union health of the mind and the health. Based on the traditional Chinese wisdom of medicine, the diseases are not necessarily the bad things, rather, they can be wisely regarded as the blessings in disguise, namely, "nature's means of reeducating the whole person." [6] The reason why most of the ordinary people get seriously ill is that they have failed to discover the entire functions of their life as a whole. The whole functions of life inevitably include the function of morality and the inner virtues.

\subsection{Overcome the Dichotomy Between Body and Mind by Living Virtuously}

One of the most serious problems that have bedeviled the health of the modern people is undoubtedly the dichotomy between the body and the mind. This kind of dichotomy has directly led to the mechanical views to the issue of health. The good human nature is actually the most important source of the healthy and self-curing power. When the good human nature "receives its proper nourishment, there is nothing which will not grow. If it lose its proper nourishment, there is 
nothing which will not decay away." As Confucius said, "Hold it fast, and it remains with you. Let it go, and you lose it." [7] (p285) By practicing the specific virtues and living the virtuous life, we are essentially deepening and broadening the potential power of life. As compared with the other animals, man lives not merely in the physical dimension of the objective world, but also in the emotional and spiritual dimensions of the subjective world. The existence of the virtues makes it possible for the human beings to surpass the physical universe to some extent and live in the midst of various virtuous emotions, in moral rules and moral imaginations, in moral hopes and the virtuous spirits. What essentially shapes the health of a person, are not just the measurable things and objective conditions, but also his spiritual level and virtuous life. "The fourth kind of people was known as Xianren (the virtuous people) who abode by the laws of the earth and the heavens, imitated the changes of the sun and the moon, followed the varying order of the stars, adhered to the changes of Yin and Yang, differentiated the four seasons, and acted in accordance with the practice of the immortal beings in ancient times. In this way they prolonged their life." [13] (p. 11-13). It is commonly admitted by the traditional Chinese medicine that virtues play an indispensable role in the healthy function of the human body. The more virtuous and integrated a person is, the less likely he will become physically ill. By cultivating the sound virtues, a person lays the sound foundation for his sound mental and spiritual health, which serves as the most important foundation of his physical health. The virtuous life reminds the virtuous agents of the significance of overcoming the feelings of being insignificant and powerless. To maintain the healthy state, the individual life is supposed to be meaningfully connected with more people and even with the universe.

\section{The Wisdom of the Traditional Chinese Medicine and Its Modern Relevance}

The vulnerable situation of the health situation of the modern people has brought about the revived confidence in the essential values of the wisdom of the traditional Chinese medicine. Despite the amazingly rapid development of the modern medical science and technology, the modern people are still suffering much from all kinds of diseases, both physically and mentally. Therefore, the modern people have come to realize the fundamental fact that the ancient wisdom of the traditional Chinese medicine can be a positive, progressive and extremely important factor in promoting the genuine health among the modern people.

\subsection{Facing the Modern Crisis of Health: Learn From the Ancient Wisdom}

Bearing the ancient wisdom of the Traditional Chinese medicine, we can possibly find an effective approach to the sustainably healthy way of life for the modern people.
Although health is the topic of perennial interest, mankind still knows little about the true wisdom that makes it possible for us to be healthy.

During the course of life, every one has to face many seemingly insurmountable difficulties. Many of the difficulties that can pose a threat to the health are actually inevitable and unavoidable. If we can not maintain the peaceful mind and the inner harmony, we can be overwhelmed by the endless anxiety and despair. By turning to the ancient Chinese medical wisdom for help, we can better make use of our mental, physical, and spiritual resources to keep fit. The body itself has the power to heal itself. Within the life lies the internal and huge potential self-healing power. Unfortunately, due to the greedy and aggressive modern life style, the modern people have greatly harmed and weakened the self-healing power. As Confucius said, "Hold it fast, and it remains with you. Let it go, and you lose it. Its outgoing and incoming can not be defined as to time or place."[7] (p 285) It is eventually up to ourselves to determine whether we can maintain our own inner health resources, which plays an essential role in our healthy life. Similarly, Mencius also said, "Therefore, if it receives its proper nourishment, there is nothing which will not grow. If it loses its proper nourishment, there is nothing which will not decay away." [7] (p 285) The ancient wisdom of traditional Chinese medicine has consistently provided us with the great healthy nourishment that is vital to our sustainable health.

\subsection{The Life of Virtue and Dignity: Search for the Meaning and Genuine Health of Life}

Life is supposed to be free and beautiful, healthy. However, it is becoming increasingly difficult for us to experience the poetic and natural feelings of living harmoniously in the harmonious world. Undoubtedly, the modern world is getting a great deal more efficient than before. Our life, at the same time, is also getting increasingly convenient, despite the fact that we feel a much higher degree of loneliness and alienation. The modern society often strikes us as being like a cold and indifferent social machine, with each individual people being just one of its replaceable parts.

From the perspective of the traditional Chinese medicine, this kind of separate and isolated state of life constitutes a huge problem for the health of the modern people. Just like the illnesses of the body reflect the objective problems of the natural environment, the diseases of the mind profoundly reflect the illnesses of the internal mental environment. The disproportionate emphasis upon the external pleasures and successes has indeed led to the deep health crisis of the modern people. When we don't pay enough attention to the health of the inner mind and the well-being of the internal soul, the so-called external health will become soulless and rootless.

\subsection{The Life Without the Guidance of the Ancient Medical Wisdom Is Not Worth Living}

The most serious and fundamental cause of the health 
crisis of the modern people is the neglect of the ancient medical wisdom, including the wisdom of Chinese medicine. As a matter of fact, the health crisis, like a mirror, clearly reflects the crisis of modernity. To put it simply, the modern people are just pursuing the superficial goals, such as the goal of being rich or the goal of being successful, at the cost of the essential fundamentals of life. Due to the grave violation of the ancient way of preserving health, the modern people are actually losing their precious health. "People nowadays, on the contrary, just behave oppositely. They drink wine as thin rice gruel, regard wrong as right, and seek sexual pleasure after drinking. As a result, their Essence-Qi is exhausted and Genuine-Qi is wasted. They seldom take measures to keep an exuberance of Jingqi and do not know how to regulate the mind or spirit, often giving themselves to sensual pleasure. Being irregular in daily life, they begin to become old even at the age of fifty." [1] (p. 3-5) When we do not respect the natural laws, we will be punished by nature, similarly, when the modern people do not follow the natural health wisdom of the ancient times, they will also pay the high price of getting ill and unfit. According to the ancient wisdom of the traditional Chinese medicine, the outer universe, or the heaven, is quite similar to the inner universe, the inner body. Therefore, only when the modern people can live in harmony with the natural laws of life can they maintain the healthy state of life. In this sense, the lifestyle of the modern people is simply anti-natural or against the natural laws of life. What is the proper and natural lifestyle that corresponds to the natural laws of the universe? According to the traditional Chinese wisdom of medicine, "In the three months of Spring, all things on the earth begin to grow. The natural world is resuscitating and all things are flourishing. People may sleep late in the night and get up early in the morning, taking a walk in the courtyard with hair running free to relax the body and enliven the mind. Such a natural resuscitating process should be activated instead of being inhibited, promoted instead of being destroyed." [1] (p 17) Similarly, during the following summer, autumn, and winter seasons, we should adapt our lifestyles on the basis of the seasonal changes.

"The awakening consciousness of Confucianism is related to the renewal of culture and the transformation of traditions in order to redefine cultural identity and to guide social and economic development."[8] The fundamental basis of health is actually the harmonious cultural identity existing within each virtue agent's heart. By finding the profound meaning of life and identifying oneself with the truly meaningful and essential aims of life, the virtue agents can indeed understand the essence of health.

"This means that a gentleman must be able to suppress personal desire in favor of public right." [9] "The perfect man has no self; the holy man has no merit; the sage has no fame." [10] By morally surpassing and transcending the ego, the virtue agent enlarge himself to be the culturally great self and can then essentially achieve the true wisdom of being healthy.

\section{Appendix}

This study was supported by Nanjing University of Traditional Chinese Medicine. (Grant No. 15ZHB007)

\section{References}

[1] Yellow Emperor's Canon of Medicine, translated into English by Li Zhaoguo, published by World Publishing Corporation, 2005.

[2] Rollo May: Man's Search For Himself, Published by W. W. Norton \& Company, Inc, p. 105.

[3] Erich Fromm: The Sane Society, Published by Routledge \& Kegan Paul, 1991, p.13.

[4] Ernst Cassirer: An Essay On Man, Published by Yale University Press, 1944, p. 40.

[5] James Legge, the Works of Mencius, pp. 79-80.

[6] Rollo May: Man's Search for Himself, Published by W. W. Norton \& Company. Inc, New York, 1953, p. 110.

[7] The Chinese Classics: The Works of Mencius, Translated by James Legge, published by Shanghai Sanlian Book Company, 2013, p. 285.

[8] XinZhong Yao: An Introduction to Confucianism, Published by Cambridge University Press, 2006, p.275.

[9] Xun zi, Basic Writing, Translated by Burton Watson, Published by Columbia University Press, 2003, p33.

[10] The Basic Writings of Chuang Tzu, Translated by Burton Watson, Published by Columbia University Press, 1996, p.26. 